\title{
ANAP

\section{DESENVOLVIMENTO ARQUITETÔNICO DE JOÃO PESSOA ENTRE 1980 E 1990}

\author{
Rayssa Raphaely Souza Martins ${ }^{1}$
}

\section{RESUMO}

Este artigo aborda o desenvolvimento arquitetônico de João Pessoa - Paraíba entre os anos 1985 e 1994, a fim de identificar a repercussão da produção arquitetônica pós-moderna na capital pessoense e suas transformações na paisagem da cidade, através dos exemplares realizados na cidade e identificados através do referencial teórico.

PALAVRAS-CHAVE: Desenvolvimento arquitetônico; Pós-moderno; João Pessoa.

\section{ARCHITECTURAL DEVELOPMENT OF JOÃO PESSOA BETWEEN 1980 AND 1990}

\section{ABSTRACT}

This article discusses the architectural development of João Pessoa - Paraíba between the years 1985 and 1994 in order to identify the impact of postmodern architectural production in pessoense capital and its transformations in the landscape of the city, through the copies held in the city and identified by the theoretical framework.

KEYWORDS : Architectural Development; Postmodern; João Pessoa.

\section{EL DESARROLLO ARQUITECTÓNICO DE JOÃO PESSOA ENTRE 1980 Y 1990}

\section{RESUMEN}

Este artículo aborda el desarrollo arquitectónico de João Pessoa - Paraíba entre los años 1985 y 1994 con el fin de identificar el impacto de la producción arquitectónica posmoderna en la capital pessoense y sus transformaciones en el paisaje de la ciudad, a través de las copias realizadas en la ciudad y identificadas por el marco teórico.

\footnotetext{
${ }^{1}$ Graduada em Arquitetura e Urbanismo pelo Centro Universitário de João Pessoa; Mestranda em Arquitetura e Urbanismo pela Universidade Federal da Paraíba. E-mail: rayssa.raphaely@gmail.com
} 


\section{ANAP $B_{r a s i l}$ \\ ISSN 1904-3240 \\ v. 8, n. 13}

\section{REVISTA CIENTIFICA}

PALABRAS CLAVE: Desarrollo Arquitectónico; Posmoderno; João Pessoa.

\section{INTRODUÇÃO}

Neste artigo o objetivo geral é identificar a produção arquitetônica realizada na cidade de João Pessoa, Paraíba, entre os anos de 1985 e 1994, a fim de apresentar a repercussão do desenvolvimento arquitetônica pósmoderno na capital.

Como métodos de análise, a revisão bibliográfica tem como objetivo fundamentar o referencial teórico. Sendo arquitetura pós-moderna o tema objeto desse referencial teórico, é possível a realização da fundamentação teórica, como a identificação da arquitetura pós-moderna em João Pessoa, através dos debates e características desta produção, com base em autores internacionais, nacionais e nos trabalhos acadêmicos que englobam o tema abordado.

As referências utilizadas neste trabalho foram organizadas em dois momentos: Arquitetura Pós-Moderna, composto pelos filósofos HABERMAS (1980, 1992, 2000) e JAMESON (2006 e 2007); pelos historiadores VENTURI (1995), ROSSI (2001), MONTANER (1993), PORTOGHESI (1999), MAHFUZ (1988), BASTOS (2010), BASTOS E ZEIN (2011) e SEGAWA (2002); e Arquitetura Pós-Moderna em João Pessoa composto pelos trabalhos acadêmicos de ARAÚJO (1988), BRITO (2005), COSTA (2012), ROCHA JÚNIOR (2012) e DINIZ (2013).

Para a identificação dos exemplares arquitetônicos produzidos em João Pessoa entre 1985 e 1994, os trabalhos acadêmicos são fontes para a identificação do cenário arquitetônico da cidade de João Pessoa entre os anos 1980 e 1990. Com isso, é possível especificar os exemplares arquitetônicos construídos contidos de elementos e características pós-modernas. 


\section{ANAP Brasil \\ ISSN 1904-3240 \\ v. 8, n. 13}

R E VISTA

CIENTIFICA

Da arquitetura moderna para arquitetura pós-moderna: Como ocorreu?

A cidade de João Pessoa, Paraíba, entre o final dos anos 1970 e o inicio dos anos 1980, foi marcada pela realização de inúmeros exemplares arquitetônicos com características eminentemente modernas (ver figuras 1, 2 e 3), mesclados à outra produção induzida pelos debates e experiências que vinham ocorrendo no país. Principalmente a partir de meados da década de 1980, a capital pessoense começou a passar por transformações pontuais em sua paisagem arquitetônica, perceptíveis, por um lado, pela inserção de obras modernas de grande porte, como o Espaço Cultural José Lins do Rego (1980) e o aeroporto Castro Pinto (1982), e por outro, por exemplares que continham características, formas e elementos propostos pelas discussões e exemplares pós-modernos.

Figura 1: À esquerda, PROMAC, ano 1974 e à direita, Residência Roberto Luna Freire, ano 1985. Obras do Arquiteto Régis Cavalcanti.

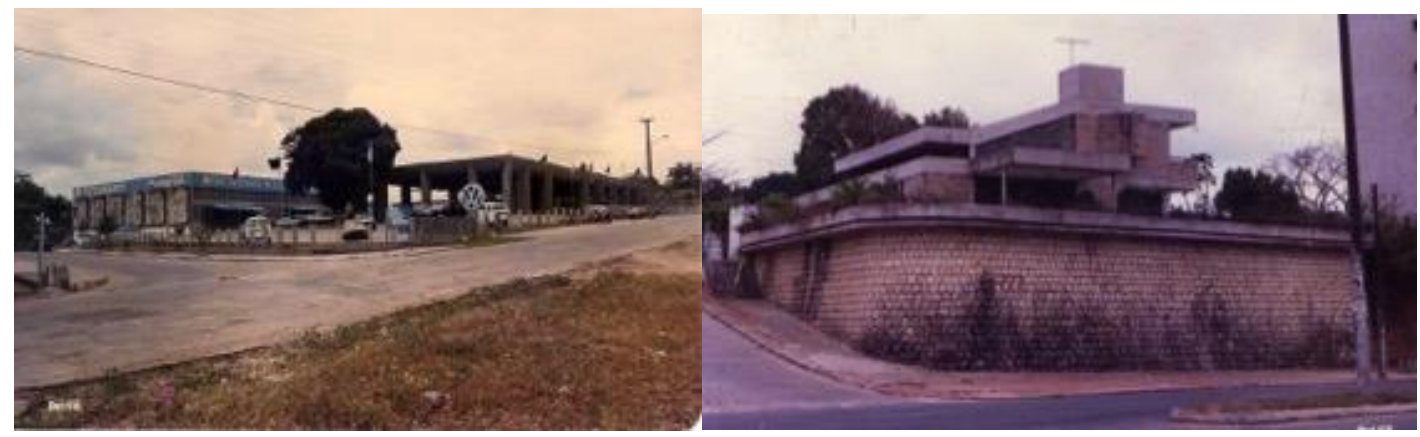

Fonte: ARAÚJO, 1988. 


\section{ANAP Brasil \\ ISSN 1904-3240 \\ v. 8, n. 13}

\section{REVISTA CIENTIFICA 2015}

Figura 2: À esquerda, Residência Gilfredo Costa, ano 1984 e à direita, TV O Norte, ano 1986. Obras do Arquiteto Amaro Muniz Castro.
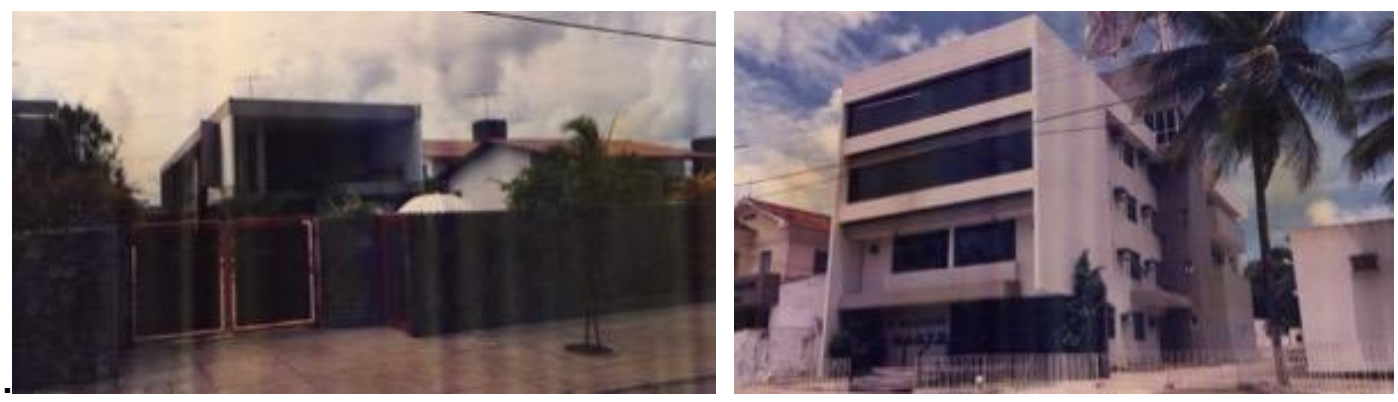

Fonte: ARAÚJO, 1988.

Figura 3: À esquerda, Residência Eduardo Cunha, ano 1984 e à direita, Edifício Fênix, ano 1982. Obras do Arquiteto Expedito Arruda.
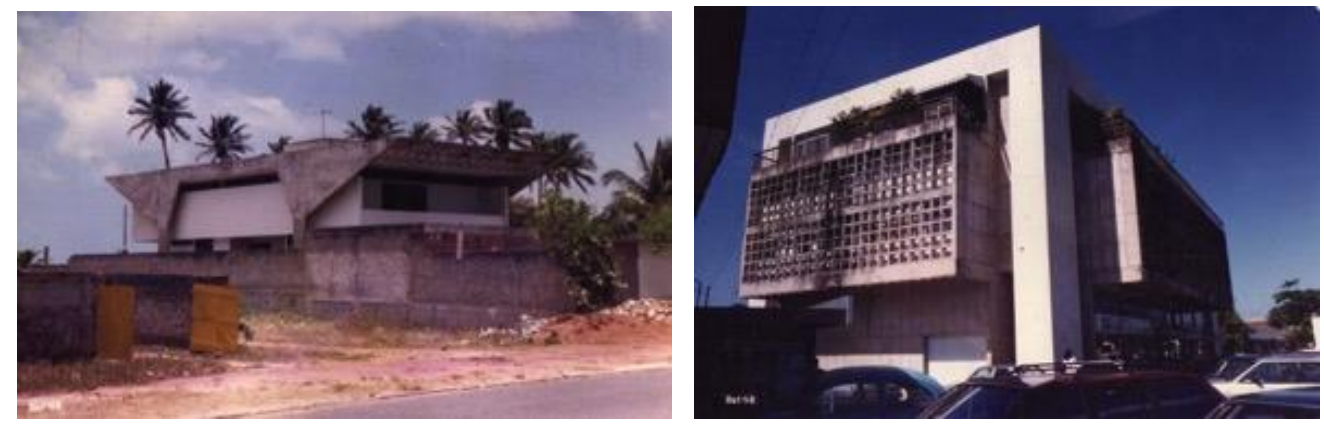

Fonte: ARAÚJO, 1988.

Concomitantemente às transformações que estavam ocorrendo na cidade, o início dos anos 1980 foram, também, marcados pela formação das primeiras turmas de profissionais arquitetos e urbanistas graduados pela Universidade Federal da Paraíba, cuja inquietação modificava o cenário arquitetônico paraibano que, com isso, apresentava alterações perceptíveis. José Wolf ${ }^{2}$ em uma publicação na revista AU em 1998 relata estas mudanças:

\footnotetext{
2 José Wolf, jornalista fundador da revista AU Arquitetura e Urbanismo, nascido em Salto SP, falecido em 2013. Trabalhou no Jornal do Brasil, na Folha de São Paulo e na Editora Pini, entre 1976 e 2002. A partir de 1985, as 15 primeiras edições foram publicadas sob sua direção editorial.
} 


\section{ANAP Brasil \\ ISSN 1904-3240 \\ v. 8, n. 13}

\section{REVISTA C I EN TIF I C A}

Expedito de Arruda, Gilberto Guedes, A. Cláudio Massa, Ernani Jr., Bethania Tejo, Débora Julinda ou Jussara Dantas são alguns protagonistas da 'inocente revolução', que se inicia nos anos 80, mudando a paisagem da doce província. Com 30 escritórios de arquitetura e um universo profissional de aproximadamente 300 arquitetos atuantes, quase $90 \%$ da produção do mercado imobiliário da capital paraibana passa atualmente pela mão de algum arquiteto. (WOLF, 1998).

Os exemplares arquitetônicos produzidos entre os anos 1985 e 1994 na cidade de João Pessoa surgem em meio às discussões acerca da revisão e crítica ao movimento moderno, que chegavam com certo atraso no Brasil, e com elas novo elementos, formas e materiais que modificavam o panorama arquitetônico. Com a inserção de exemplares arquitetônicos que apresentavam características formais distintas da produção existente na capital, João Pessoa começa a sofrer alterações perceptíveis em sua paisagem.

A revista AU, em 1988, publicou uma matéria intitulada "Vida no 'satélite' verde" (ver figura 4), em que, ao seu critério, selecionou quatro escritórios de arquitetura para expor suas ideias acerca da produção arquitetônica realizada em João Pessoa naquele período.

Figura 4: Edição de número 19, capa e matéria intitulada "Vida no "satélite“ verde".
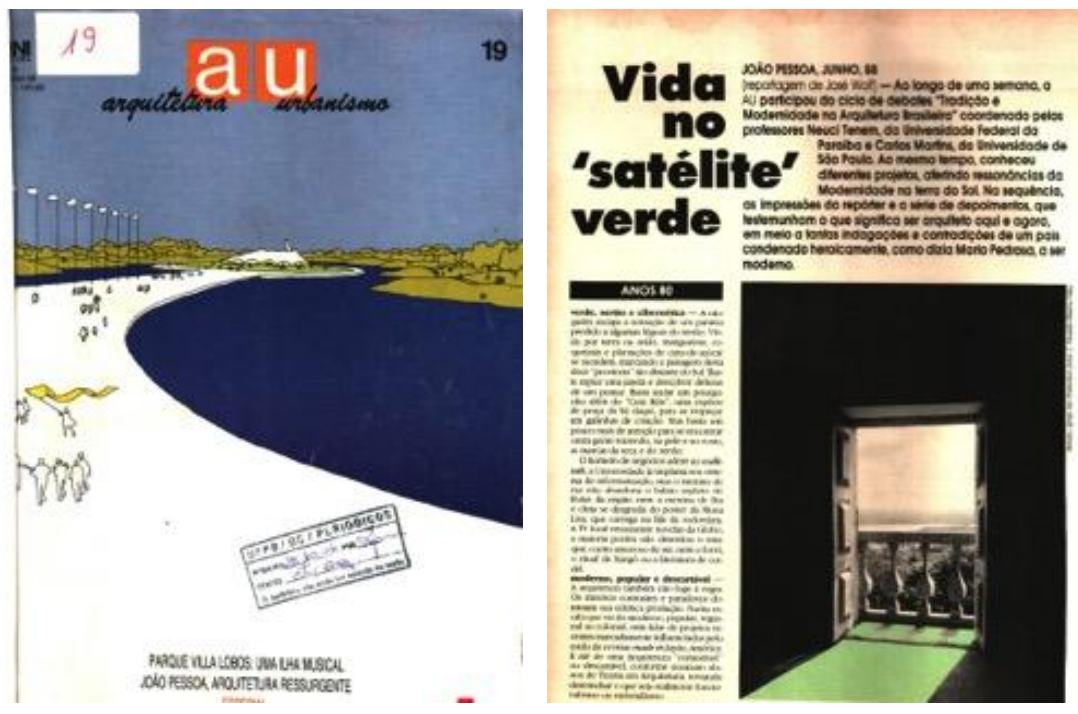

Fonte: Revista AU, nº 19, setembro de 1988.

Revista Científica ANAP Zrasd, v. 8, n. 13, 2015, p. 56-68. 


\title{
ANAP Brasil \\ ISSN 1904-3240 \\ v. 8, n. 13
}

Os escritórios de arquitetura selecionados por José Wolf são dos arquitetos: Mario Glauco Di Lascio, Cláudio Massa e Ernani Henrique, Régis Cavalcanti e Expedito Arruda. O primeiro personagem, Mario Di Lascio, ao ser questionado sobre arquitetura pós-moderna, responde que mesmo com o desenvolvimento de produções arquitetônicas pós-moderna, ele ainda se encontra bastante sedimentado dentro do Movimento Moderno.

\begin{abstract}
O volume de produções da Arquitetura Moderna, como disse, ainda é significativo, enquanto o pós começa a dar os primeiros passos, a nível principalmente de uma sociedade de consumo, para epater le ourgeois... Mas meu futuro é hoje. Portanto, dentro da sedimentação histórica, as minhas propostas de projetação são modestas nessa linha do pós, mas bastante justificadas e sedimentadas dentro do Movimento Moderno. Me sinto, enfim, recorrendo à linguagem do caçador, de tocaia... . (Revista AU, n 19 , setembro de 1988, p. 67.)
\end{abstract}

Os arquitetos Cláudio Massa e Ernani Henrique, formados na Universidade Federal da Paraíba, ao serem questionados por José Wolf acerca de do pós-moderno enquanto pesquisa e linguagem, responderam de forma cautelosa, que assim como a grande maioria, eles também se encontravam curiosos diante das novidades arquitetônicas, porém, enquanto estrutura, essência ou avanço arquitetônico, ainda não existia respaldo suficiente para executa-la.

Naturalmente desde os tempos de estudante (responde Massa), todo mundo estava curioso pelas novidades. E, de certa forma, a gente ficou nesse passo também. De repente, somos bombardeados por uma série de informações externas, o que acontece atualmente em João Pessoa, como você observou. Exemplos de um pós-moderno que poderia estar em qualquer rua de Nova York ou numa cidade da Europa. Mas, enquanto estrutura, essência ou avanço real de nossa Arquitetura, não temos ainda respaldo suficiente para isso. (Revista AU, no 19 , setembro de 1988, p. 68.)

Régis Cavalcanti, arquiteto formado na Universidade Federal de Pernambuco, que ao ser indagado sobre qual tipo de linguagem arquitetônica passa pela sua prancheta, responde afirmando que essa questão de linguagem 


\title{
ANAP Brasil \\ ISSN 1904-3240 \\ v. 8, n. 13
}

REVISTA CIENTIFICA 2015

algo muito individual, pois para ele a Arquitetura é arte, mais arte que tecnologia, sabendo que a tecnologia surge para auxiliar a execução do projeto. Ao ser questionado sobre o pós-moderno, Régis é enfático ao dizer que falta uma compreensão do que realmente é o pós-moderno. Pois na sua visão, qualquer coisa com duas colunas e triângulo já é considerado pós.

\begin{abstract}
Acho apenas que está havendo muita confusão, está faltando entender o que seja realmente pós-moderno. Qualquer coisa que se faça com duas colunas e um triângulo já se fala em pós, não é por aí. O pós implica todo um contexto cultural europeu ou americano, que provavelmente não tem nada a ver com a gente. As condições daqui são outras, não temos os coliseus e as venezas da vida, nossas referências são outras. (Revista AU, № 19, setembro de 1988, p. 70.)
\end{abstract}

Com isso, ele afirma que se encontra em "um momento de decantação, estamos passando por uma verdadeira revolução, mas uma revolução positiva, de enriquecimento da própria Arquitetura". (Revista AU, no 19, setembro de 1988, p. 70).

Expedito Arruda, arquiteto formado na Universidade Federal de Pernambuco, que ao ser indagado sobre como situa sua linguagem arquitetônica atual, responde afirmando a busca pelo desenvolvimento de uma linguagem dentro do pós-moderno, por considerar que a arquitetura moderna já não trazia respostas suficientes para o seu tipo de trabalho.

\footnotetext{
Procuro desenvolver uma linguagem dentro da escala do chamado pós-moderno, tentando criar elementos vinculados ao pós, mas que não se limitem a uma Arquitetura ornamental. Veja essa trilogia, os edifícios Guarujá, Água Viva e a casa-galpão, são apenas elaborações que poderíamos chamar de pele, fachadas sem alterações significativas em termos de espaço. (Revista AU, no 19 , setembro de 1988, p. 72).
}

A inquietação que resultou na idealização deste artigo, se deu inicialmente por entrevistas realizadas com o arquiteto Expedito Arruda durante o meu trabalho de conclusão de curso, intitulado "Régis Cavalcanti, Amaro Muniz, Expedito Arruda e o legado arquitetônico moderno na cidade de João 


\section{ANAP $B_{r a s i l}$ \\ ISSN 1904-3240 \\ v. 8, n. 13}

Pessoa entre 70 e 80", realizado em 2012, em que o mesmo relatou numa entrevista, que durante o início dos anos 1980 a arquitetura moderna já não o satisfazia como antes, e por isto os elementos pós-modernos começavam a fazer parte de sua produção arquitetônica.

Este relato, feito a mim pelo arquiteto em 2012, foi identificado anos antes na publicação da revista AU em 1988, como foi citado anteriormente, no qual me fez questionar se esta arquitetura pós-moderna que ele disse ter realizado em João Pessoa entre os anos 1980 e 1990, realmente havia acontecido. Então, a fim de responder a questão da existência desta produção, este artigo se deterá em identificar alguns dos exemplares que compõe este cenário arquitetônico em João Pessoa.

Entre os anos 1960 a 1990, a arquitetura pós-moderna internacional foi se desenvolvendo, sendo o auge desta produção e debate os anos 1980. Este movimento surgiu com o objetivo de estabelecer a crítica à arquitetura moderna, principalmente ao estilo internacional. PORTOGHESI (1999) relata as características presentes na arquitetura pós-moderna, sendo estas, contrapostas aos princípios modernos, em que propõe a pluralidade dos estilos e a dupla maneira de atender ao gosto popular e aos especialistas, através da rememoração do passado e da transparência no qual esta produção é realizada.

Para o Portoghesi, o Pós-moderno mais que uma tendência, representava um horizonte pluralista, que por muitos anos foi tratado superficialmente, que "consistia em acrescentar às usuais tipologias modernistas alguns sinais da nova vulgata: uma abóbada de vidro, uma claraboia piramidal, um tímpano desproporcionado aplicado à cobertura" (PORTOGHESI, 1999, p.19), e que não passou de uma moda, fundamentar-se apenas nisto para descrever a produção Pós-moderna é um erro grave.

Portanto, limitar com precisão o que é a arquitetura pós-moderna, destacando um conjunto de atributos que a distinguem das demais, isto é, que podem ser utilizados como critério para sua classificação e reconhecimento, 


\section{ANAP $B_{r a s i l}$ \\ ISSN 1904-3240 \\ v. 8, n. 13}

não é consistente com o ideário pluralista pós-moderno, que tinha como diretriz recusar os valores universais em favor da multiplicidade de discursos. Por isto, tende a evitar retratar o pós-modernismo como um estilo uniforme.

Em virtude dessa dificuldade para caracterizar o pós-modernismo com poucos dados estilísticos, o crítico Charles Jencks, responsável por difundir o uso do vocábulo pós-moderno entre os arquitetos, reuniu "mais de trinta normas e formas que definem o movimento". Dentre elas, é possível ressaltar o pluralismo, a complexidade, a contradição, a representação irônica e metafórica, a ornamentação simbólica, os sistemas de duplas e de múltiplas codificações e referências, o ecletismo, o pastiche histórico, entre outros.

A delimitação do recorte temporal foi realizada inicialmente através de observações empíricas proporcionadas pelas pesquisas no acervo fotográfico do Arquiteto Ricardo Araújo, bem como, através de pesquisas pessoais, no qual foi possível observar uma mudança formal nas obras de arquitetura a partir de meados da década de 1980. A partir dos anos 1985 as transformações no invólucro arquitetônico das construções, foram marcadas por características distintas das obras já existentes na capital paraibana. Estas transformações são citadas por alguns trabalhos acadêmicos, como: ARAÚJO (1988), BRITO (2005), COSTA (2012), ROCHA JÚNIOR (2012) e DINIZ (2013), bem como, em publicações realizadas pela revista AU.

\section{RESULTADOS E CONCLUSÕES}

A partir das pesquisas e análises dos trabalhos acadêmicos, foi possível realizar a construção de um cardápio arquitetônico ${ }^{3}$, formado por exemplares construídos em João Pessoa entre os anos 1980 e 1990 (ver

\footnotetext{
${ }^{3}$ O cardápio arquitetônico de João Pessoa entre os anos 1980 e 1990, foi realizado a partir das pesquisas em revistas, trabalhos acadêmicos e acervos fotográficos, sendo possível apresentar neste artigo apenas uma pequena parte do todo.
}

Revista Científica ANAP Zrasd, v. 8, n. 13, 2015, p. 56-68. 


\section{ANAP $B_{\text {rasil }}$ \\ ISSN 1904-3240 \\ v. 8, n. 13}

\section{REVISTA CIENTIFICA}

figuras 5,6 e 7), no qual estão inseridos alguns exemplares contidos de elementos e características oriundos da arquitetura pós-moderna.

Ao realizar as pesquisas acerca da arquitetura pós-moderna, foi verificada a pluralidade de correntes, tendências e debates acerca da produção arquitetônica realizada após 1960. Portoghesi (1999), Montaner (1993), Moneo (2008), convergem ao apontar a existência de três expoentes que representam a ideia da busca por um impulso para uma renovação arquitetônica, mesmo realizando propostas diferentes, são eles: Robert Venturi, Aldo Rossi e Peter Eisenman.

A partir de características formais oriundas das propostas dos três arquitetos expoentes deste período, são identificadas representações irônicas, pastiche histórico, referências, ornamentação simbólica, entre outras, existentes em alguns exemplares construídos entre 1980 e 1990, com isso foi possível observar que o início desta produção deu-se a partir do Edifício Guarujá construído em 1985, por ser o primeiro exemplar identificado e registrado em trabalhos acadêmicos e na revista $A U$, constituído de elementos que indicam referência em tais características. E como critério de organização de pesquisa, que busca identificar um período da produção arquitetônica de João Pessoa contidas de características pós-moderna, este artigo se estende até o ano 1994, marcado pela construção da Concessionária Peugeot, a pioneira no uso das estruturas metálicas para além das soluções estéticas, ou seja, sua estrutura voltada aos elementos necessários ao suporte da edificação, caracterizando a tecnologia construtiva como partido arquitetônico. 


\section{ANAP

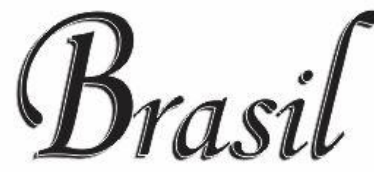 \\ ISSN 1904-3240 \\ v. 8, n. 13}

\section{REVISTA CIENTIFICA 2015}

Figura 5: À esquerda, Ed. Guarujá, ano 1985 e à direita, Ed. Água Viva, ano 1986. Obras do Arquiteto Expedito Arruda.
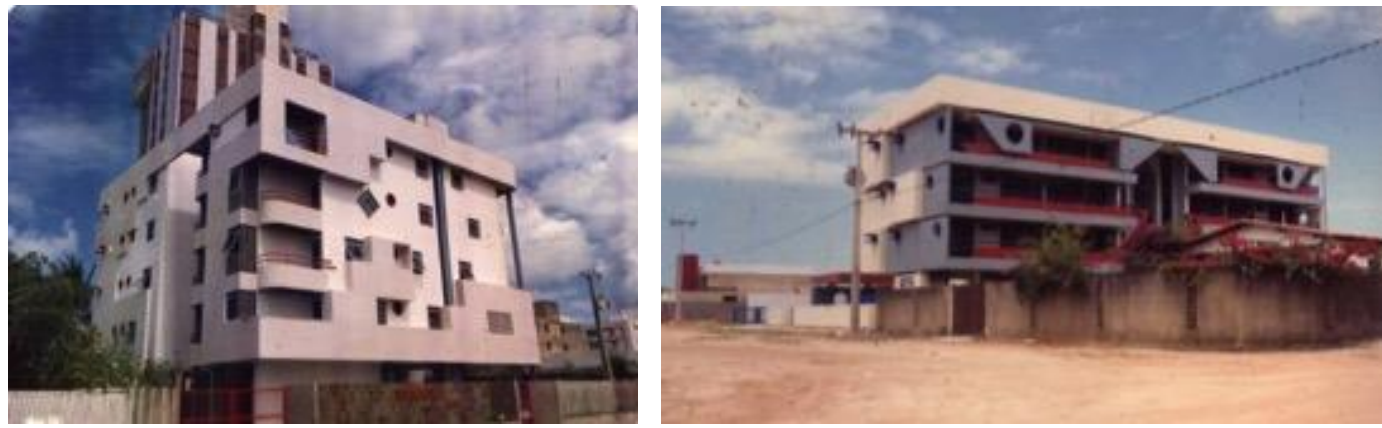

Fonte: ARAÚJO, 1988.

Figura 6: À esquerda, Mercado de Artesanato de João Pessoa, ano 1988 a 1991. Obra dos Arquitetos Amaro Muniz e Régis Cavalcanti e à direita, Ed. Atrium, ano 1985. Obra do Arquiteto: Expedito Arruda.
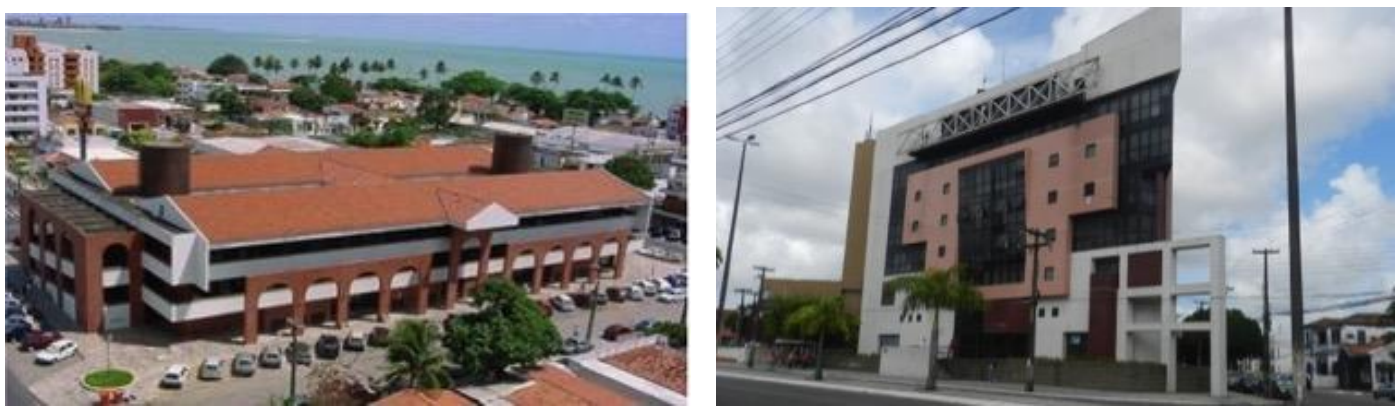

Fonte: http://mercadodeartesanatopb.blogspot.com.br e Acervo Pessoal (2014).

Figura 7: À esquerda, Residência do Arquiteto Gilberto Guedes, 1991 a 1999 e à direita, Concessionária Peugeot, 1994. Obras do Arquiteto Gilberto Guedes.

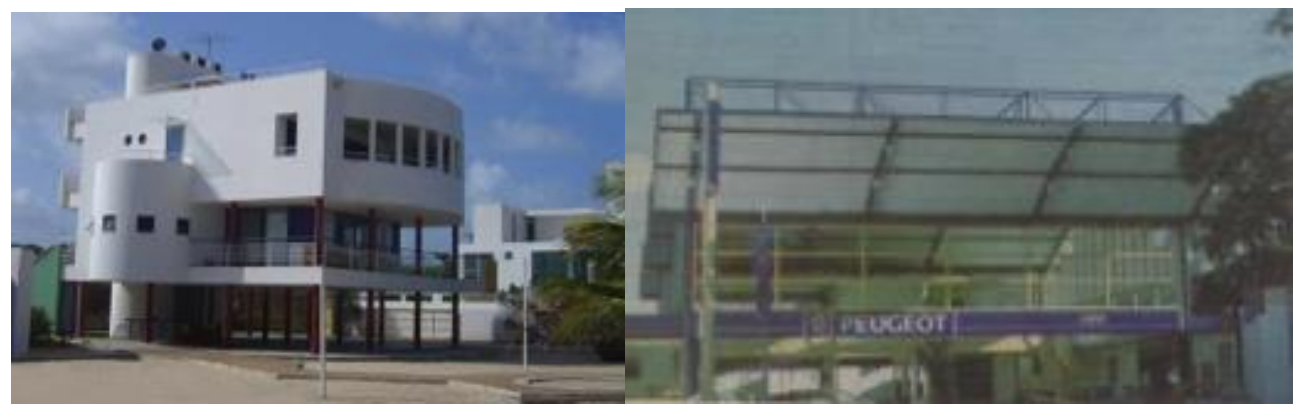

Fonte: ROCHA JÚNIOR, 2012.

Revista Científica ANAP Zrasd, v. 8, n. 13, 2015, p. 56-68. 


\section{ANAP

Portanto, este artigo apresenta de forma breve a arquitetura produzida em João Pessoa entre os anos 1980 e 1990, tendo como foco a identificação dos exemplares arquitetônicos que foram produzidos neste recorte temporal, contidos por características que fazem referência ao debate arquitetônico pósmoderno, a fim de apresentá-los como parte do desenvolvimento da cidade.

\section{REFERÊNCIAS BIBLIOGRÁFICAS}

ARAÚJO, Ricardo Ferreira. Aspectos plástico-formais da arquitetura contemporânea em João pessoa: 1980 - 1988. Trabalho Final de Graduação no curso de Arquitetura e Urbanismo - UFPB. João Pessoa: UFPB, 1988.

BASTOS, Maria Alice Junqueira; ZEIN, Ruth Verde. Brasil: arquiteturas após 1950. São Paulo: Perspectiva, 2011.

BASTOS, Maria Alice Junqueira. Pós-Brasília: Rumos da arquitetura brasileira. São Paulo: Perspectiva: FAPESP, 2010.

BRITO, Ana Laura de F. R. O Metal na arquitetura contemporânea paraibana: 1990-2002. Dissertação (Mestrado em Arquitetura e Urbanismo) - Programa de Pós-graduação em Arquitetura e Urbanismo, Universidade Federal do Rio Grande do Norte, Natal, 2005.

COSTA, Carolina. O pós-moderno na arquitetura nordestina (1985-2000). 2012. Dissertação (Mestrado em Arquitetura e Urbanismo) - Programa de Pós-graduação em Arquitetura e Urbanismo, Universidade Federal do Rio Grande do Norte, Natal, 2012.

GUERRA, A. Textos fundamentais da arquitetura moderna brasileira_parte 1. São Paulo, Romano Guerra, 2010.

HABERMAS, Juergen. Arquitetura versus Pós-Modernidade, in: Novos Estudos CEBRAP, São Paulo - Publicação quadrimestral. Edição utilizada: Setembro/1980.

Arquitetura moderna e pós-moderna, 1987. In ARANTES, Otília. Um ponto cego no projeto moderno de Jurgen Habermas, São Paulo: Brasiliense, 1992 Martins Fontes, 2000.

O Discurso Filosófico da Modernidade. trad. Luis Repa. São Paulo:

JAMESON,Fredric. A virada cultural: reflexões sobre o pós-moderno. Rio de Janeiro: Civilização Brasileira, 2006.

Paulo: Ática, 2007.

Pós-Modernismo: a lógica cultural do capitalismo tardio. 2.ed. São

MAHFUZ, E. C. Quem tem medo do pós-moderismo. Revista Projeto, n. 111, 1989. 


\section{ANAP

MONTANER, Josep Maria. Después del movimiento moderno: arquitetura de la segunda mitad del siglo XX. Barcelona: Gustavo Gili, 1993.

PORTOGHESI, Paolo. Depois da Arquitetura Moderna. Lisboa: Edições 70, 1999.

ROCHA JÚNIOR, Rui Vanderlei. Construção Arquitetônica Contemporânea: a obra de Gilberto Guedes. 2012. Dissertação (Mestrado em Arquitetura e Urbanismo) - Programa de Pós-graduação em Arquitetura e Urbanismo, Universidade Federal da Paraíba, João Pessoa, 2012.

ROSSI, Aldo. Arquitetura da cidade. 2. Ed. São Paulo: Martins Fontes, 2001.

SEGAWA, Hugo. Arquitetura no Brasil: 1900-1990. 2. ed. São Paulo: Editora da Universidade de São Paulo, 2002.

VENTURI, Robert. Complexidade e contradição em arquitetura. São Paulo: Martins Fontes, 1995, Tradução Álvaro Cabral (1a ed. 1966).

WOLF, José. Algo de novo na terra do sol...arquitetura paraibana, sim senhor!. AU (Arquitetura e Urbanismo), São Paulo, n.79, p. 78- 84, ago./set. 1998.

\section{Periódico}

REVISTA AU. Edição de número 19, Editora Pini, setembro de 1988. 